\title{
Atomic-Scale Dynamics of the Formation and Dissolution of Carbon Clusters in $\mathrm{SiO}_{2}$
}

\author{
Sanwu Wang, ${ }^{1, *}$ Massimiliano Di Ventra, ${ }^{1, \dagger}$ S. G. Kim, ${ }^{1, \ddagger}$ and Sokrates T. Pantelides ${ }^{1,2, \S}$ \\ ${ }^{1}$ Department of Physics and Astronomy, Vanderbilt University, Nashville, Tennessee 37235 \\ ${ }^{2}$ Solid State Division, Oak Ridge National Laboratory, Oak Ridge, Tennessee 37831
}

\begin{abstract}
Oxidation of $\mathrm{SiC}$ produces $\mathrm{SiO}_{2}$ while $\mathrm{CO}$ is released. A 'reoxidation' step at lower temperatures is, however, necessary to produce high-quality $\mathrm{SiO}_{2}$. This step is believed to cleanse the oxide of residual $\mathrm{C}$ without further oxidation of the $\mathrm{SiC}$ substrate. We report first-principles calculations that describe the nucleation and growth of O-deficient $\mathrm{C}$ clusters in $\mathrm{SiO}_{2}$ under oxidation conditions, fed by the production of $\mathrm{CO}$ at the advancing interface, and their gradual dissolution by the supply of $\mathrm{O}$ under reoxidation conditions. We predict that both $\mathrm{CO}$ and $\mathrm{CO}_{2}$ are released during both steps.
\end{abstract}

PACS numbers: 68.55.Ln, 81.40.-z, 68.35.Dv

The most significant property of semiconductors is their ability to sustain heterogeneous $n$-type and $p$-type doping. This property, however, is eroded by high temperatures and high voltages that cause intrinsic excitation of electron-hole pairs across the band gap. As a result, semiconductors with significantly larger band gaps than silicon have been investigated as candidates for electronic devices suitable for high temperatures and high voltages. Silicon carbide is a particularly attractive candidate because its native oxide is $\mathrm{SiO}_{2}$ which works so well as a dielectric in Si-based microelectronics. The presence of a third element, however, namely $\mathrm{C}$, results in a wide range of phenomena that do not occur in the $\mathrm{Si}-\mathrm{SiO}_{2}$ system. In particular, oxidation of $\mathrm{SiC}$ entails the production of $\mathrm{CO}$ which effuses through the oxide [1,2]. Afanas'ev et al. have suggested that carbon clusters at and near the interface form during oxidation [3, 1 , but the structure and dynamics of these clusters has not been established. Lipkin and Palmour found that, after oxidation, a 'reoxidation' step is necessary to produce high-quality oxides and $\mathrm{SiC}_{-} \mathrm{SiO}_{2}$ interfaces $[5,6$. this step, oxygen is supplied as during oxidation, but the temperature is lowered so that no further oxidation takes place. In contrast, post-oxidation heat treatment without the supply of $O$ leads to an increase of charged defects in the oxide [7]. It is believed that the 'reoxidation' step cleanses the interface and bulk $\mathrm{SiO}_{2}$ of residual carbon [3]. Duscher et al. recently presented direct experimental evidence for the existence of carbon in as-grown samples and its removal after reoxidation [8].

The nucleation and growth of impurity clusters in semiconductors is a generic problem for which totalenergy calculations are well suited to provide detailed information. In this Letter we present the results of extensive first-principles density-functional calculations that allow us to give a detailed account of the nucleation and growth of O-deficient carbon clusters in $\mathrm{SiO}_{2}$ during oxidation conditions and their dissolution during reoxidation conditions. Basically, a CO molecule, generated at the advancing interface and diffusing through the oxide, can bind weakly to an $\mathrm{O}$ site in the $\mathrm{SiO}_{2}$ network. A second $\mathrm{CO}$ molecule, however, can bind to the first and the new complex is very stable. Additional CO molecules can extend the cluster. The process is helped by a passing $C O$ that takes an $O$ atom from the cluster and effuses as $\mathrm{CO}_{2}$. The net result is O-deficient clusters. During 'reoxidation' at reduced temperatures, no further oxidation of the $\mathrm{SiC}$ substrate occurs so that no $\mathrm{CO}$ is produced. Instead, the supply of $\mathrm{O}$ atoms is used to 'oxidize the $\mathrm{C}$ clusters'. The process leads to the gradual dissolution of the $\mathrm{C}$ clusters through the formation of both $\mathrm{CO}$ and $\mathrm{CO}_{2}$. These results account for the available data and lead to a prediction that can be tested, namely the effusion of $\mathrm{CO}_{2}$ during both oxidation and reoxidation. Note in particular that, during oxidation, there is simultaneous reoxidation, accounting for the fact that the concentration of $\mathrm{C}$ clusters is not excessive and that substantial amounts of $\mathrm{CO}$ are in fact released. In contrast, during reoxidation, only dissolution of the clusters occurs.

The objective of the calculations was to determine one or more sequences of steps that lead to the formation of $\mathrm{O}$-deficient $\mathrm{C}$ clusters by the aggregation of $\mathrm{CO}$ molecules and simultaneous release of $\mathrm{O}$. Thus, sequences of stable configurations were determined. Determination of the barriers for the formation of theses configurations is a laborious task because of the multitude of atoms that are involved. Test calculations were carried out in several cases by assuming specific pathways. Typical barriers were smaller than $1 \mathrm{eV}$. Since the calculations represent upper bounds and the relevant temperatures are above $1000^{\circ} \mathrm{C}$, the processes identified in this paper do in fact occur.

The calculations were performed within density functional theory, using the pseudopotential method and a plane wave basis set. The exchange-correlation effects were treated with local density approximation in the form of Ceperley and Alder [9]. We adopted the Vanderbilt ultrasoft pseudopotentials [10]. A plane wave energy cutoff 
of 40 Ry was used. All the structures were fully relaxed. Similar to earlier work [11], the calculations for the structure relaxation were conducted with one $\mathbf{k}$ point at $(0.5$, $0.5,0.5$ ), while the densities of states (DOS) were calculated with 14 inequivalent $\mathbf{k}$ points.

A supercell $\left(9.60811 \times 10.93795 \times 10.62372 \AA^{3}\right)$ containing 72 atoms, generated by Tu et al. [12] with a Monte Carlo bond-switching method [13], was used to model the amorphous $\mathrm{SiO}_{2}$. This model corresponds to a density of $2.15 \mathrm{~g} / \mathrm{cm}^{3}$ for the amorphous $\mathrm{SiO}_{2}$, close to the experimental value of $2.20 \mathrm{~g} / \mathrm{cm}^{3}$ at the standard pressure. The calculated DOS was found to be in good agreement with the experimental photoemission spectra 14] and previous first-principles calculations [15, 16], which used different structure models to simulate the amorphous $\mathrm{SiO}_{2}$. The $\mathrm{SiO}_{2}$ band gap was calculated to be $5.6 \mathrm{eV}$, the same as in earlier calculations [16].

$\mathrm{CO}$ molecules in a perfect $\mathrm{SiO}_{2}$ network. We assume that the advancing interface during oxidation emits $\mathrm{CO}$ molecules, as found in Refs. [1] and 2, and explore the possible reactions that $\mathrm{CO}$ molecules can undergo in the $\mathrm{SiO}_{2}$ matrix. A perfectly bonded network without any defects is first considered. We find that a single $\mathrm{CO}$ molecule can bind to a network $\mathrm{O}$ atom. The bound configuration (hereafter [CO]) is shown in Fig. 1(a). There is a $\mathrm{Si}-\mathrm{C}-\mathrm{O}-\mathrm{Si}$ bridge with the extra $\mathrm{O}$ atom attached to the $\mathrm{C}$ atom so that the integrity of the $\mathrm{CO}$ molecule is preserved. The bondlength of the $\mathrm{CO}$ molecule is now $1.21 \AA, 0.07 \AA$ longer than the bondlength of a free $\mathrm{CO}$ molecule at an open interstitial site in $\mathrm{SiO}_{2}$ (hereafter $\left.\mathrm{CO}^{(\text {free })}\right)$. While this $\mathrm{C}-\mathrm{O}$ bond is more likely a double-bond, another $\mathrm{C}-\mathrm{O}$ bond between the carbon and the original bulk oxygen atom appears to be a singlebond (with a bondlength of $1.36 \AA$ ). The total energy of the $[\mathrm{CO}]$ configuration is $0.23 \mathrm{eV}$ lower than that of the $\mathrm{CO}^{(\text {free })}$. This is a rather small binding energy, suggesting that both structures can exist. The energy cost for the release of a $\mathrm{CO}$ molecule from $\mathrm{SiO}_{2}$ is calculated to be $0.18 \mathrm{eV}$. Hence, $\mathrm{CO}$ molecules at the open interstitial sites can easily escape from $\mathrm{SiO}_{2}$, as found by experiments [1].

The binding energy of a $\mathrm{CO}$ molecule in the $[\mathrm{CO}]$ configuration, though small, is sufficient to result in a substantial fraction of $\mathrm{CO}$ molecules being bound at any given time [about 9 out of 10 , as estimated from $\exp (-\Delta E / k T)$ with $\Delta E=0.23 \mathrm{eV}$ and $k T=0.1 \mathrm{eV}]$. When a diffusing $\mathrm{CO}$ molecule encounters a $[\mathrm{CO}]$, it can be attached to form a two-molecule complex, $\left[\mathrm{C}_{2} \mathrm{O}_{2}\right]$, via the reaction

$$
[C O]+C O^{(\text {free })} \rightarrow\left[\mathrm{C}_{2} \mathrm{O}_{2}\right] .
$$

The energy gain is $1.6 \mathrm{eV}$, which suggests strong binding. The $\left[\mathrm{C}_{2} \mathrm{O}_{2}\right]$ configuration is shown in Fig. 1(b). The complex forms a bridge across a network ring with the two halves of the bridge being on different planes.
When a third CO molecule gets near the $\left[\mathrm{C}_{2} \mathrm{O}_{2}\right]$ structure, instead of binding, it takes one of the oxygen atoms from the cluster and forms either a $\mathrm{CO}_{2}$ molecule at an open interstitial site $\left(\mathrm{CO}_{2}^{(\text {free })}\right.$ configuration) or a $\mathrm{CO}_{2-}$ like bonded configuration ( $\left[\mathrm{CO}_{2}\right]$, shown in Fig. 1(c)). The $\left[\mathrm{CO}_{2}\right]$ configuration has essentially the same total energy as $\mathrm{CO}_{2}^{(\text {free) }}$ (only $0.04 \mathrm{eV}$ lower, which is within the uncertainty of the calculations). The remaining bonded configuration $\left(\left[\mathrm{C}_{2} \mathrm{O}\right]\right)$ contains two carbon and one additional oxygen atoms, as shown in Fig. 1(d). This structure is similar to the $\left[\mathrm{C}_{2} \mathrm{O}_{2}\right]$ configuration except for having one less oxygen atom. The above process responsible for the formation of $\mathrm{CO}_{2}$ is exothermic with a energy gain of $0.8 \mathrm{eV}$. Such a reaction can be expressed as:

$$
\left[\mathrm{C}_{2} \mathrm{O}_{2}\right]+\mathrm{CO}^{(\text {free })} \rightarrow\left[\mathrm{C}_{2} \mathrm{O}\right]+\mathrm{CO}_{2}^{(\text {free })}+0.8 \mathrm{eV} .
$$

We conclude that oxidation of $\mathrm{SiC}$ results in the release of both $\mathrm{CO}$ and $\mathrm{CO}_{2}$. There are no experimental reports about $\mathrm{CO}_{2}$ being released. Special effort would be needed to detect it because it is probably present in the chamber already.

As more $\mathrm{CO}$ molecules arrive, the $\left[\mathrm{C}_{2} \mathrm{O}\right]$ complex undergoes additional reactions. First, a $\mathrm{CO}$ molecule binds to the $\left[\mathrm{C}_{2} \mathrm{O}\right]$ structure which results in the formation of a $\left[\mathrm{C}_{3} \mathrm{O}_{2}\right]$ configuration, shown in Fig. 2(a). The complex contains one $\mathrm{C}-\mathrm{O}$ double bond and two $\mathrm{C}-\mathrm{O}$ single bonds with bondlengths of $1.15 \AA$ and $1.31 \AA$, respectively. The bondlengths of the two C-C bonds are $1.31 \AA$ and 1.37 $\AA$. The energy gain is again very large, $2.0 \mathrm{eV}$.

The $\left[\mathrm{C}_{3} \mathrm{O}_{2}\right]$ configuration is a very stable defect. The arrival of yet another $\mathrm{CO}$ molecule does not lead to further growth. Though another $\mathrm{CO}$ can be attached to $\left[\mathrm{C}_{3} \mathrm{O}_{2}\right]$, there is an energy cost of $0.54 \mathrm{eV}$, which makes the reaction highly unlikely. Similarly, a passing $\mathrm{CO}$ molecule cannot take away an $\mathrm{O}$ atom from $\left[\mathrm{C}_{3} \mathrm{O}_{2}\right]$ and become $\mathrm{CO}_{2}$. The process again involves energy cost $(0.22 \mathrm{eV})$. If, however, by coincidence, two $\mathrm{CO}$ molecules happen to arrive at a $\left[\mathrm{C}_{3} \mathrm{O}_{2}\right]$ complex at the same time (a rare event), the reaction

$$
\left[\mathrm{C}_{3} \mathrm{O}_{2}\right]+2 \mathrm{CO}^{(\text {free })} \rightarrow\left[\mathrm{C}_{4} \mathrm{O}_{2}\right]+\mathrm{CO}_{2}^{(\text {free })}
$$

can occur with an energy gain of $1.3 \mathrm{eV}$. The resulting $\left[\mathrm{C}_{4} \mathrm{O}_{2}\right]$ complex is shown in Fig. 2(b). Once it forms, this complex can again lose an $\mathrm{O}$ atom to a passing $\mathrm{CO}$, becoming a $\left[\mathrm{C}_{4} \mathrm{O}\right]$ complex, shown in Fig. 2(c). The gain in energy is $1.4 \mathrm{eV}$.

The $\left[\mathrm{C}_{4} \mathrm{O}\right]$ is unstable, however. Upon the arrival of a $\mathrm{CO}$ molecule, the following reaction occurs

$$
\left[\mathrm{C}_{4} \mathrm{O}\right]+\mathrm{CO}^{(\text {free })} \rightarrow\left[\mathrm{C}_{3} \mathrm{O}_{-2}\right]+2 \mathrm{CO}_{2}^{(\text {free })}+1.1 \mathrm{eV}
$$

with an energy gain of $1.1 \mathrm{eV}$. Two $\mathrm{CO}_{2}$ molecules are released and the residual defect $\left[\mathrm{C}_{3} \mathrm{O}_{-2}\right]$ consists of three $\mathrm{C}$ atoms in the space of two $\mathrm{O}$ vacancies [Fig. 2(d)]. This 
last defect is stable against the arrival of one or two $\mathrm{CO}$ molecules.

In summary, we have shown that through a process of complex reactions $\mathrm{CO}$ molecules passing through $\mathrm{SiO}_{2}$ will form oxygen-deficient carbon complexes through the emission of $\mathrm{CO}_{2}$ molecules. The most stable defects are $\left[\mathrm{C}_{3} \mathrm{O}_{2}\right]$ and $\left[\mathrm{C}_{3} \mathrm{O}_{-2}\right]$. The formation of the latter, however, necessitates an intermediate step that requires the simultaneous arrival of two $\mathrm{CO}$ molecules.

$\mathrm{CO}$ molecules in $\mathrm{SiO}_{2}$ with $\mathrm{O}$ vacancies. When oxygen vacancies exist in bulk $\mathrm{SiO}_{2}$, a $\mathrm{CO}$ molecule fills a vacancy by forming two $\mathrm{Si}-\mathrm{C}$ bonds. The resulting configuration is shown in Fig. 1(e) (thereafter as [C]). The $\mathrm{C}-\mathrm{O}$ bond is a double-bond with a bondlength of $1.23 \AA$. The binding energy of the $\mathrm{CO}$ molecule in the $[\mathrm{C}]$ structure (relative to the molecule in the $\mathrm{CO}^{\text {(free) }}$ structure) is $2.2 \mathrm{eV}$. However, this structure is not stable. When an additional $\mathrm{CO}$ molecule arrives, the $[\mathrm{C}]$ structure transforms into the $\left[\mathrm{C}_{2} \mathrm{O}\right]$ structure [Fig. 1(d)]. The energy gain is $3.0 \mathrm{eV}$.

Reoxidation. We now examine the reactions that can occur during reoxidation when no new $\mathrm{CO}$ molecules are produced but oxygen is available.

First, defects containing a single carbon atom such as $[\mathrm{C}]$ and $[\mathrm{CO}]$ can be removed in the form of $\mathrm{CO}_{2}$ molecules through the following processes:

$$
\begin{gathered}
{[C]+O \rightarrow[C O]+8.8 \mathrm{eV},} \\
{[C O]+O \rightarrow C O_{2}^{(\text {free })}+8.1 \mathrm{eV} .}
\end{gathered}
$$

Second, clusters of two carbon atoms, ie., those in the $\left[\mathrm{C}_{2} \mathrm{O}\right]$ and $\left[\mathrm{C}_{2} \mathrm{O}_{2}\right]$ configurations can be dissociated and released in the form of $\mathrm{CO}$ and $\mathrm{CO}_{2}$ molecules as follows,

$$
\begin{aligned}
{\left[\mathrm{C}_{2} \mathrm{O}\right] } & +\mathrm{O} \rightarrow\left[\mathrm{C}_{2} \mathrm{O}_{2}\right]+7.6 \mathrm{eV} \\
{\left[\mathrm{C}_{2} \mathrm{O}_{2}\right] } & +\mathrm{O} \rightarrow \mathrm{CO}^{(\text {free })}+\mathrm{CO}_{2}^{(\text {free })}+6.6 \mathrm{eV} .
\end{aligned}
$$

Similarly, the three-carbon clusters will be removed through the following reactions:

$$
\begin{aligned}
{\left[C_{3} O_{-2}\right]+O } & \rightarrow\left[C_{3} O_{-1}\right]+6.7 \mathrm{eV} \\
{\left[C_{3} O_{-1}\right]+O } & \rightarrow\left[C_{3}\right]+6.8 \mathrm{eV} \\
{\left[C_{3}\right]+O } & \rightarrow\left[C_{3} O\right]+7.5 \mathrm{eV} \\
{\left[C_{3} O\right]+O } & \rightarrow\left[C_{3} O_{2}\right]+8.6 \mathrm{eV} \\
{\left[C_{3} O_{2}\right]+O } & \rightarrow\left[C_{2} O\right]+C_{2}^{(\text {free })}+6.3 \mathrm{eV} .
\end{aligned}
$$

Finally, the clusters with four carbon atoms will lose one carbon atom and reduce to three-carbon clusters as follows,

$$
\begin{aligned}
{\left[\mathrm{C}_{4} \mathrm{O}\right]+\mathrm{O} } & \rightarrow\left[\mathrm{C}_{4} \mathrm{O}_{2}\right]+7.0 \mathrm{eV} \\
{\left[\mathrm{C}_{4} \mathrm{O}_{2}\right]+O } & \rightarrow\left[\mathrm{C}_{3} \mathrm{O}_{2}\right]+C \mathrm{O}^{(\text {free })}+7.0 \mathrm{eV}
\end{aligned}
$$

The $\mathrm{C}_{3}$ clusters will then be removed with further reoxidation, as shown in Equs. (13), (7), and (8).
In summary, we have shown that the $\mathrm{CO}$ molecules that are generated during oxidation of $\mathrm{SiC}$ diffuse through the network and can form a large variety of complexes containing one, two, three, and four $\mathrm{C}$ atoms. One key result is that these defects are oxygen deficient, as $\mathrm{O}$ atoms are removed by combining with $\mathrm{CO}$ molecules forming $\mathrm{CO}_{2}$ molecules. This phenomenon provides a natural explanation of the 'reoxidation' step since we also showed that a supply of oxygen can dissolve the C clusters.

We would like to thank G. Duscher and L. C. Feldman for useful discussions. This work has been supported by the Defense Advanced Research Program Agency grant MDA972-98-1-0007, the Electrical Power Research Institute grant WO806905, NSF grant DMR-9803768, the Division of Materials Sciences, US Department of Energy under contract DE-AC05-960R22464, and the William A. and Nancy F. McMinn Endowment at Vanderbilt University.

* Present address: The School of Computational Science and Information Technology, and Center for Materials Research and Technology, Florida State University, Tallahassee, Florida 32306. Electronic mail: swang@csit.fsu.edu.

$\dagger \quad$ Present address: Department of Physics, Virginia Polytechnic Institute and State University, Blacksburg, Virginia 24061.

¥ Present address: WISEnut, Inc., Santa Clara, California 95051.

§ Electronic mail: panterlides@vanderbilt.edu.

[1] J. Tan, M.K. Das, J.A. Cooper, Jr., and M.R. Melloch, Appl. Phys. Lett. 70, 2280 (1997).

[2] M.Di Ventra and S.T. Pantelides, Phys. Rev. Lett. 83, 1624 (1999); J. Electron Mater. 29, 353 (2000).

[3] V.V. Afanas'ev, A. Stesmans, M. Bassler, G. Pensl, M.J. Schulz, and C.I. Harris, Appl. Phys. Lett. 68, 2141 (1996).

[4] M. Bassler, G. Pensl, and V. Afanas'ev, Diamond and Related Mater. 6, 1472 (1997); V.V. Afanas'ev, M. Bassler, G. Pensl, and M. Schultz, Phys. Status Solidi A 162, 321 (1997).

[5] L.A. Lipkin and J.W. Palmour, J. Electron. Mater. 25, 909 (1996).

[6] G.Y. Chung, C.C. Tin, J.R. Williams, K. McDonald, M.Di Ventra, S.T. Pantelides, L.C. Feldman, and R.A. Weller, Appl. Phys. Lett. 76, 1713 (2000).

[7] J.N. Shenoy, J.A. Cooper Jr., and M.R. Melloch, Appl. Phys. Lett. 68, 803 (1996).

[8] G. Duscher, R. Buzko, S.W. Wang, S.G. Kim, M.Di Ventra, S.J. Pennycook, J.K. McDonald, R.A. Weller, L.C. Feldman, and S.T. Pantelides, Appl. Phys. Lett., submitted.

[9] D.M. Ceperley and B.J. Alder, Phys. Rev. Lett. 45, 566 
(1980).

[10] D. Vanderbilt, Phys. Rev. B. 41, 7892 (1990).

[11] M. Boero, A. Pasquarello, J. Sarnthein, and R. Car, Phys. Rev. Lett. 78, 887 (1997).

[12] Y.H. Tu, J. Tersoff, G. Grinstein, and D. Vanderbilt, Phys. Rev. Lett. 81, 4899 (1998).

[13] F. Wooten, K. Winer, and D. Weaire, Phys. Rev. Lett. 54, 1392 (1985);

[14] B. Fischer, R.A. Pollak, T.H. DiStefano, and W.D. Grobman, Phys. Rev. B. 15, 3193 (1977).

[15] J. Sarnthein, A. Pasquarello, and R. Car, Phys. Rev. Lett. 74, 4682 (1995).

[16] M.-Z. Huang, L. Ouyang, and W.Y. Ching, Phys. Rev. B. 59, 3540 (1999).

FIG. 1. Schematics of several species containing one and two C atoms: (a) $[\mathrm{CO}]$; (b) $\left[\mathrm{C}_{2} \mathrm{O}_{2}\right] ;$ (c) $\left[\mathrm{CO}_{2}\right]$; (d) $\left[\mathrm{C}_{2} \mathrm{O}\right]$; and (e) $[\mathrm{C}]$ configurations. The dark circles denote $\mathrm{C}$ atoms. The larger and smaller grey circles are for $\mathrm{Si}$ and $\mathrm{O}$ atoms, respectively.

FIG. 2. The minimum-energy structures corresponding to the configurations containing clusters with three and four $\mathrm{C}$ atoms in $\mathrm{SiO}_{2}$ : (a) $\left[\mathrm{C}_{3} \mathrm{O}_{2}\right]$; (b) $\left[\mathrm{C}_{4} \mathrm{O}_{2}\right]$; (c) $\left[\mathrm{C}_{4} \mathrm{O}\right]$; and (d) $\left[\mathrm{C}_{3} \mathrm{O}_{-2}\right]$. 


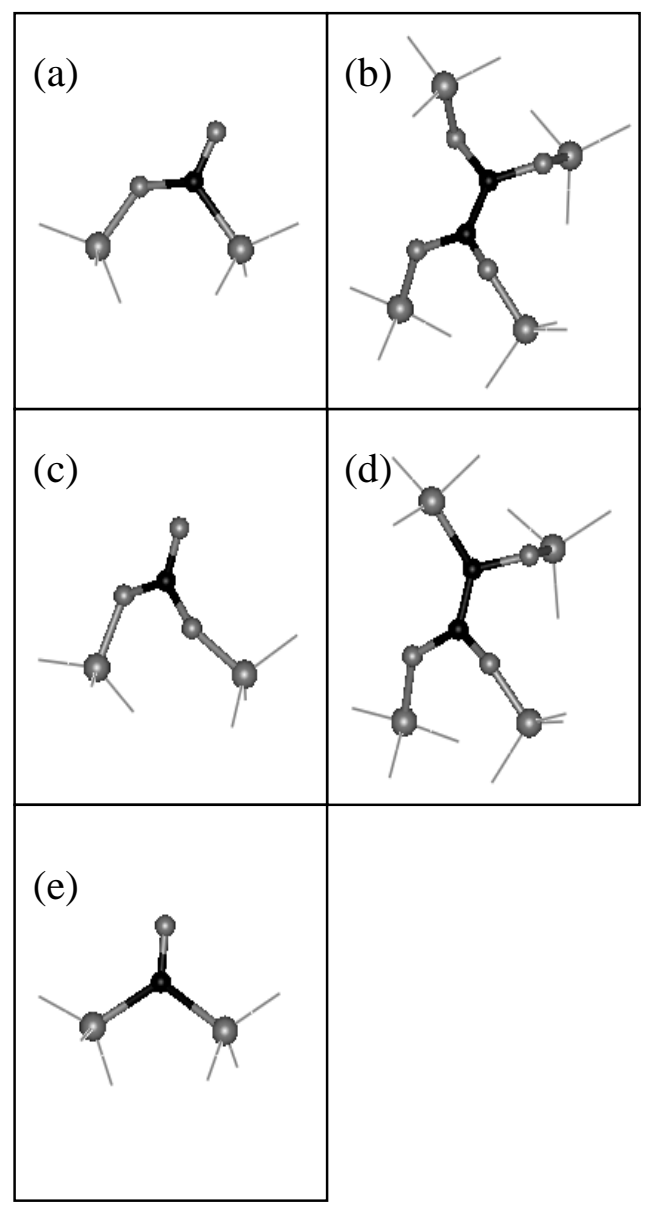




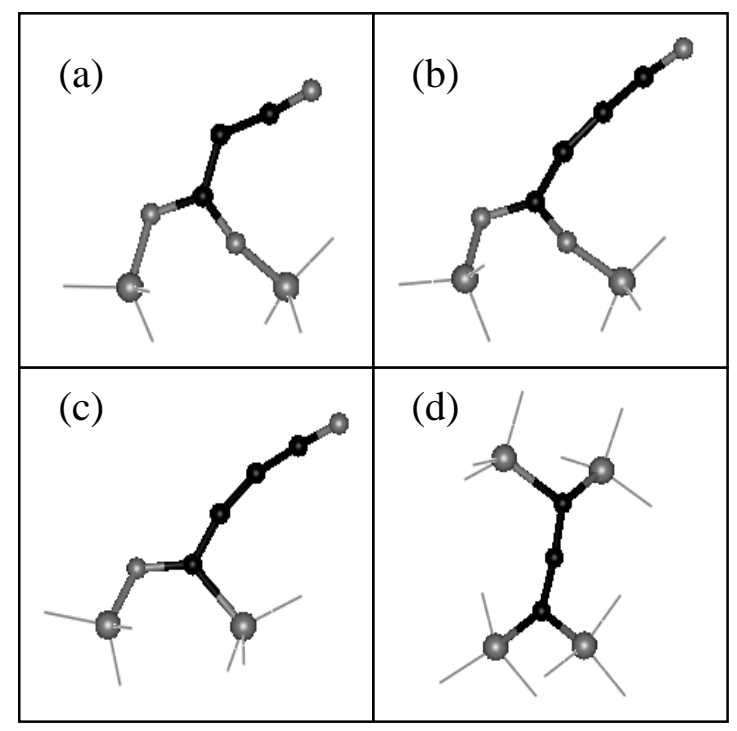

